\title{
Sivrisineklerden Koruyucu Tekstil Ürünlerinin İncelenmesi
}

\author{
*1 İsmail Yüce \\ ${ }^{1}$ Trakya University, Techincal Science Vocational School, Edirne - Turkey
}

\section{Özet}

Böcek ve sinek gibi haşereler günlük yaşantımızda istenmeyen ve zarar verebilen canlı türleridir. Genel olarak, sivrisinekler, sinekler, keneler, pireler, bitler, karıncalar vs. gibi eklembacaklılar, ısırılmasından sonra insanlara ölümcül hastalıkların yayılmasına neden olan parazitler ve patojenler taşıyabilirler. Eklem bacaklılar arasında sivrisinekler dünyadaki en ölümcül hayvanlardan biridir. Her yıl ortalama 500 milyona varan sitma vakası yaşanmakta ve bunların \% 90'1 Afrika'da gerçekleşir. Dang dünyadaki en önemli sivrisinek kaynaklı virus hastalığıdır. Dünya çapında 2,5 milyar insan enfeksiyon riski altındadır ve 100 den fazla ülkede her yıl 20 milyondan fazla vaka görülür. Bu problemin önüne geçilmesi için losyon, spray, bileklik gibi ürünler piyasada satılmaktadır. Ancak, koruyucu tekstil ürünleri tüm vücudu kapsayabildiği ve konforu nedeniyle daha kullanışlıdırlar. Bu tür koruyucu giysiler, böcek itici giysiler olarak adlandırılır. Onların işlevi, insanları genel olarak böcek ya da eklembacaklıların 1sırmasından korumaktır. Aynı zamanda uzun süreli koruma sağlaması için, bu giysiler birden fazla yıkamaya dayanıklı olmalıdır.

$\mathrm{Bu}$ çalışmada sivrisinek koruyucu tekstil ürünleri, üretim metodları ve bu kumaşların etkinliğinin ölçüm yöntemleri kaynak taraması metoduyla incelenmiştir.

Anahtar Kelimeler: Koruyucu kumaşlar, İticilik, Sivrisinek, Eklembacaklılar

\section{An Analysis of Mosquito Repellent Textile Products}

\begin{abstract}
Insects such as spider and fly are harmful species that are not desired in our daily lives. Generally, such arthropods as fly, mosquito, tick and ants can carry parasites and pathogens that can cause human beings to pick up malignant diseases after bitten by them. Among these arthropods, mosquitoes are one of the most malignant animals in the world. Each year about 500 million malaria cases are observed, $90 \%$ of which occur in Africa. Dang is the most important mosquito-borne virus disease in the world. Worldwide, 2.5 billion people are at risk of infection and more than 20 million cases occur every year in over 100 countries. In order to prevent this problem, some products like lotion, spray and wristbands are sold in the market. However, textile products that protects from insects more practical because of their comfort and their whole body covering feature. These protective fabrics are called insectrepellent textiles. The main function of these fabrics is to protect humans from insects or arthropods. These fabrics are also wash-resistant.

This study analyses insect-repellent fabrics, their production and the efficiency measurement methods by means of literature review.
\end{abstract}

Key words: Protective fabrics, Repellency, Mosquito, Arthropods 


\section{Giriş}

Dünyada 3000'den fazla sivrisinek türü vardır; ancak üç çeşit sivrisinek türü ölüm ve hastalıklara neden olmaktadır. Bunlar: Aedes, Culex ve Anopheles türü sivrisineklerdir.

Dang humması (Dang ateşi), Aedes cinsi sivrisinekler tarafından taşınır ve bulaştırılır. Dang ateşi tüm dünyada tropikal ve subtropikal bölgelerde endemik olarak görülen, şiddetli grip benzeri semptomlara neden olan viral bir hastalıktır. Son zamanlarda Aedesaegypti ve Aedesalbopictus türü sivrisineklerden bulaşan zika virüsü ortaya çıkmıştır. Afrika, Güneydoğu Asya, Pasifik Adaları ve Amerika' da zika salgınları meydana gelmiştir [3]. Dünya genelinde 2016 yılında sıtma virüsü kaynaklı 216 milyon vaka kaydedildi ve 445.000'i ölümle sonuçlanmıştır. UNICEF kayıtlarına göre sıtma hastalığı günde 1200 'den fazla çocuğun ölümüne neden oluyor [11], [13].

Sıcakkanlı canlılarda bulunan karbondioksit ve laktik asit, sivrisinekler için çekici bir madde görevi görür. Sivrisinek kovucu kimyasallar, sivrisinekleri çeken insan kokusunu maskelemek için cilde uygulanır. Bunların herhangi bir yan etkisinin olmaması ve kalıcılığının uzun süreli olması istenir. $\mathrm{Bu}$ nedenle sinek kovucu uygulanan tekstil ürünleri direkt cilde temas etmediği ve daha uzun ömürlü oldukları için avantaj yaratırlar.

Böcek koruyucu kumaşlar, böcek ısırığına ve böcek kaynaklı hastalıklara karşı koruyucu bariyer görevi gören, genellikle ev tekstil ürünleri, giysiler, askeri üniformalar ve perdeler gibi ürünleri içeren tekstil ürünleridir. Böcek öldürücü veya kovucu özelliklere sahip koruyucu tekstiller ve giysiler, böcek itici tekstil ve giysiler olarak adlandırılır. Bu tekstil ürünlerinin işlevi, insanları böcek ya da eklembacaklıların 1sırmasından korumaktır. Böcek kovucu tekstil ürünlerinin birden fazla yıkamaya dayanıklı olması istenir.

Böcek kovucu olarak en çok kullanılan iticiler, DEET (N, N-dietil-3-metilbenzamid), IR3535 (Ethyl Butylacetylaminopropionate), Icaridin (Picaridin), esansiyel yağlar ve doğal bitkisel ürünlerdir [2].

\section{Sivrisinek İtici Maddeler ve Tekstillere Kazandırma Yöntemleri}

Böcek öldürücü-kovucu özelliklere sahip kumaşlar, sentetik veya doğal böcek kovucu kimyasalların tekstil ürünleri üzerine aplikasyonu ile elde edilir. Böcek kovan bu giysiler genel olarak böcek öldürücü ve böcek kovucu olarak ikiye ayrılabilir [3].

Tekstil ürünlerine uygulanan en yaygın sivrisinek kovucu, sivrisineklere ve diğer böceklere karş1 mükemmel bir iticiliği olan DEET ve Permetrin'dir. Permetrin, krizantem çiçeklerinden elde edilen doğal bir kovucudur. Binlerce Amerikan ve İngiliz askeri üniformasında böcek kovucu ajan olarak kullanılmıştır [1], [3], [6], [11]. Permetrin aynı zamanda Birleşik Devletler Çevre Koruma Ajansına göre kullanılan tek böcek veya sinek kovucu kimyasaldır [14].

Sentetik sinek kovucular insan sağlığı için sakıncalı olabilmektedir. Örneğin sık kullanılan DEET, 6 aya kadar olan çocuklarda ve hamile kadınlar için tavsiye edilmez. IR3535 daha az 
toksiktir, 6 aylıktan daha büyük çocuklar ve hamile kadınlar için reçete edilebilir. Bu nedenle IR3535, daha düşük toksik seviyesi nedeniyle en iyi seçenek olmuştur [2]. Sentetik kovucuların yan etkilerinden dolayı bitkisel kaynaklı sivrisinek kovucular alternatif olarak kullanım alanı bulmaktadır. Bu bitkiler arasında; kadife çiçeği, fesleğen, krizantem, sardunya, sitronella yağı, limon otu yağı gibi birçok doğal kökenli iticiler vardır [6], [7], [12].

Sentetik veya doğal sinek kovucuların kumaş üzerine aplike edilmeleri çeşitli metotlarla olabilmektedir. Bunlar arasında; fulardlama-kurutma, kaplama, emdirme, püskürtme gibi metotlar vardır [18], [19], [20], [21], [22].

Böcek kovucu ile muamele edilen ağlar (cibinlikler), sivrisinek ısırığı için hem fiziksel bir bariyer hem de böcek öldürücü görevi görürler (Şekil 1). Ağlar, dokuma veya örgü kumaştan elde edilebilir ve gözenek büyüklükleri 1,2-1,5 mm arasında olur (2 mm'den daha büyüklerde sinek geçebilir). Bu ağlar genellikle polyester, polipropilen ve sentetik liflerden oluşur. Ağların fiziksel özelliklerinden dolayı kullanıcıların alerjik reaksiyonları etkilenebilir. Bu nedenle, ağ yapımında doğal elyaf kullanımı tercih nedenidir. Ancak, etkin maddenin lif ile bağ yapması sentetik liflere kıyasla daha düşük olmaktadır [15], [17].

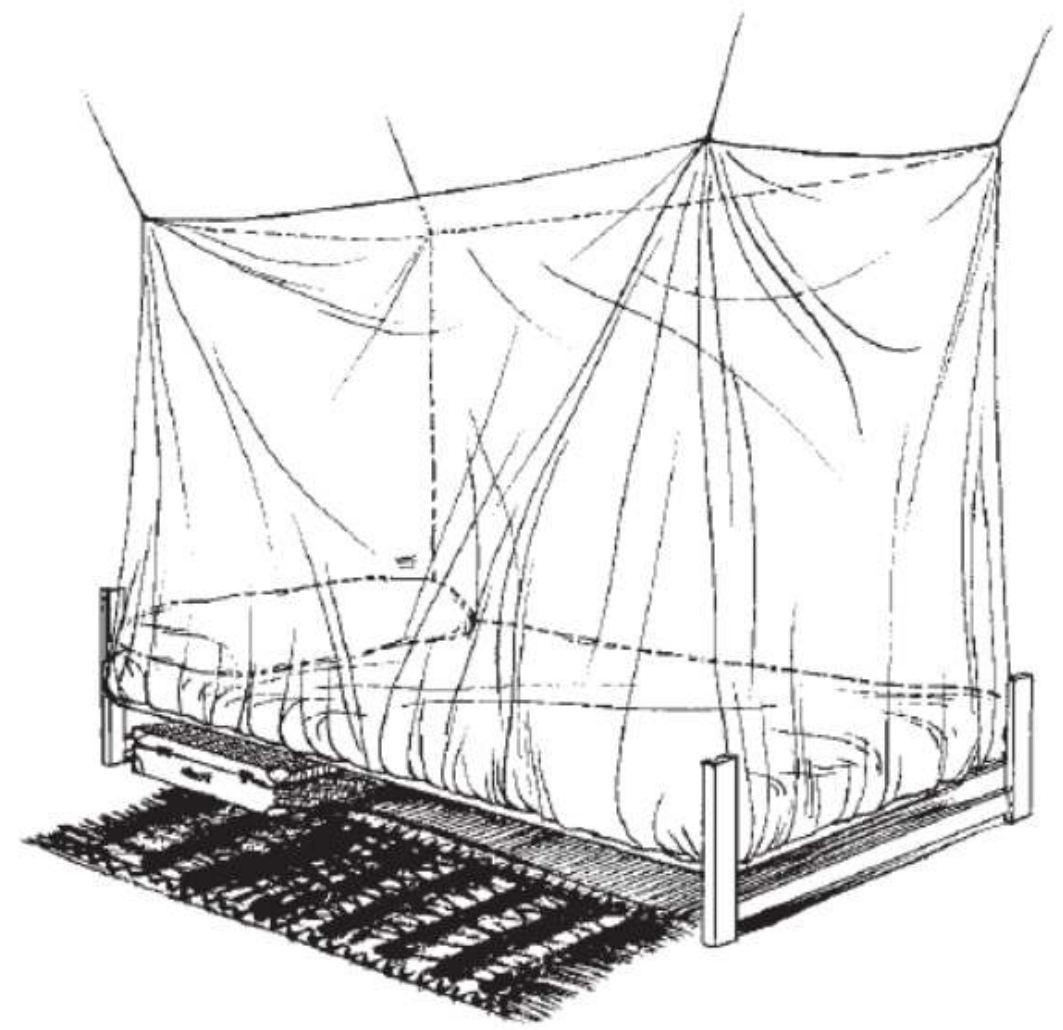

Şekil 1. Sivrisinek ve diğer eklembacaklılardan koruyucu yatak ağı (cibinlik) [17].

Böcek itici maddeler, elyaf, iplik, kumaş veya giysi üretim aşamalarında tekstil ürünlerine dahil edilebilir. Örneğin, lif çekimi sırasında permetrin gibi bir böcek iticinin liflere dahil edilebileceği bildirilmiştir [3], [9], [15]. 
Böcek itici tekstil ürünlerinin birden fazla yıkamaya dayanıklı olmaları gerekir. Bu nedenle, böcek/sinek itici kimyasalların kapsüllenerek kumaşlara uygulanması ile kalıcılık arttırılabilir. Kapsüller, uçucu kimyasalı zamanla dışarıya salacağından sinekleri uzaklaştırma etkileri daha uzun olabilmektedir. Salınım çok miktarda olursa kumaşın sinek kovucu etkisi yüksek olur ancak etkin maddenin tükenmesi hızlı olacağından kullanım ömrü kısalır. Bununla birlikte, salınım az olursa kullanım ömrü uzar ancak sineklerden koruyuculuk düşük olabilir. Bu nedenle salınımın kontrolü en optimum şekilde ayarlanmalıdır [3].

Specos ve arkadaşları yaptıkları bir çalışmada, citronella yağı içeren mikro kapsülleri, \%100 pamuklu bezayağı dokuma kumaşa uygulamışlar ve sivrisinek kovuculuğunu test etmişlerdir. Mikrokapsüllenmiş citronella yağı içeren kumaşlar ile uçucu citronella yağın bir etanol çözeltisi ile püskürtülmüş kumaşlar iticilik bakımından kıyaslanmıştır. Mikrokapsüllü kumaşların daha uzun süreli bir koruma sunarak üç hafta boyunca \% 90'dan daha yüksek bir itici etki sağladığı gözlenmiştir [7].

Anitha ve arkadaşlarının yaptıkları bir çalışmada, limon otu yağı kapsüllenerek \% 100 polyester kumaşlara uygulanmıştır. Elde edilen sonuçlara göre \% 92 oranında kovucu etki elde edilmiştir [12].

Kumaşların sivrisinek kovuculuğunun uzun süreli olması, etkin maddenin elyaf çekimi sırasında lif içine katılması ile de mümkün olabilmektedir. Örneğin, Sumitomo Chemical (Japonya) firması, elyaf çekimi sırasında permetrin katılması ile üretilen polietilen monofilamentlerinden Olyset ${ }^{\circledR}$ Net ticari adıyla sinek kovucu ağlar üretmişlerdir [10].

Sibanda ve arkadaşlarının yaptıkları bir çalışmada, sinek kovucu lif üretilerek bu lifler kullanılarak çorap örülmüştür. Çalışmada böcek kovucu özellikli bikomponent lif üretilmiştir. Lifin dış kısmı yüksek yoğunluklu polietilenden oluşurken çekirdek kısmı DEET içeren poly(ethylene-co-vinyl acetate) liften oluşur. Çalışma sonucu elde edilen ürünün, 20 soğuk yıkama ve 33 haftaya kadar sinekleri kovma özelliğini koruduğu kanıtlanmıştır [11].

Herhangi bir kimyasal kullanılmadan, sivrisineklerden koruyucu tekstil ürünleri üzerinde de çalışmalar yapılmıştır. Shannon tarafindan yapılan bir patent çalışmasında sivrisineklerden ve diğer eklem bacaklılardan koruyucu diş mekan giysisi üretilmiştir. Bu kumaş iki tabakadan oluşmakta ve dış tabakası sivrisineklerin geçişini önleyici ağ şeklinde örgü kumaş içermektedir. İki kumaş arasındaki mesafe sayesinde sivrisineğin tene ulaşması mümkün olmamaktadır (Şekil 2) [16]. 


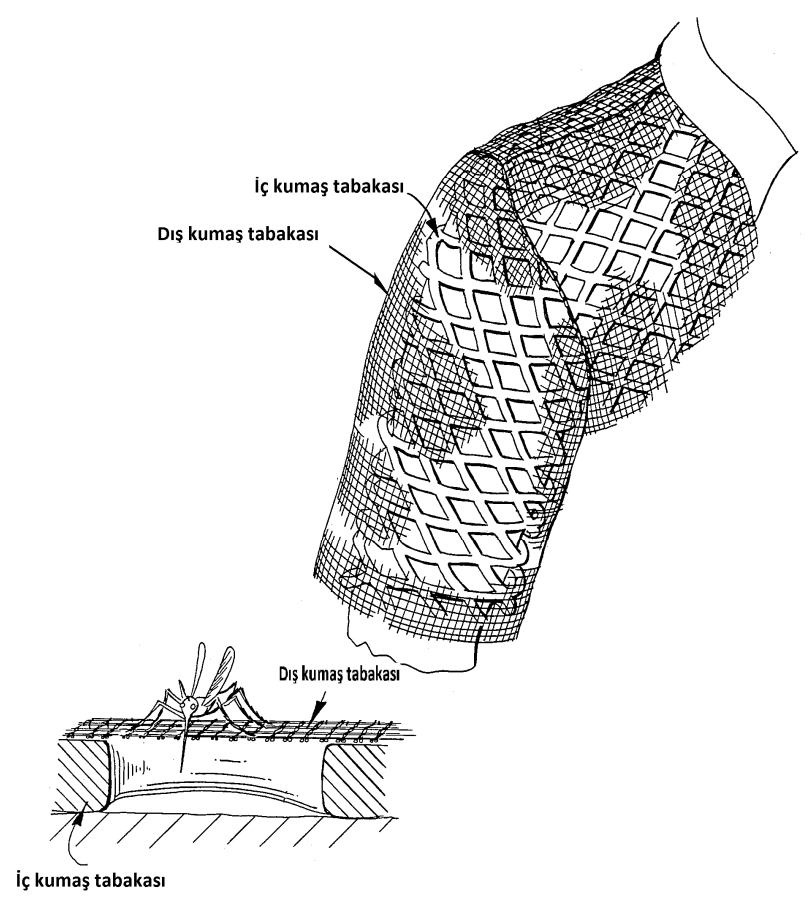

Şekil 2. Sivrisinekten koruyucu giysi tasarımı [16].

\section{Böcek İtici Tekstillerin Test Yöntemleri}

Sivrisinek kovucu ile muamele edilmiş tekstilleri değerlendirmek için çeşitli yöntemler vardır. En çok kullanılan teknikler kafes testi, koni testi ve eksito odasıdır.

\subsection{Kafes Testi}

Sivrisinek kovucuları için en sık kullanılan yöntem kafes testidir. Bu yöntem, topikal kovucular (kremler, losyonlar ve sprey formülasyonları) ve emdirme işlemi uygulanmış kumaşların değerlendirilmesi için uygundur. $\mathrm{Bu}$ yöntemde, bir kafes içerisine konulmuş sivrisinek davranışları gözlenir. Denek, işlenmiş ve konvansiyonel kumaşı ayrı ayrı giyer ve daha sonra deneğin üzerine sivrisineklerin konması gözlenir. $\mathrm{Bu}$ yöntemin avantajları arasında, sivrisineklerin insana konması ve 1sırması görülür ve aynı zamanda, kovucu ile muamele edilmiş kumaşa karşı sivrisinek hareketi doğrudan doğruya gözlenebilmektedir. Kafes testinin dezavantajı ise insan deneklerini içermesidir. İnsan katılımı açısından, gönüllülerin onayı ve bir otoritenin etik onayı aranmalıdır. Testte kullanılan sivrisineklerin patojenlerden arındırılmış olması gerekir. Böylece denekler testin onlara zarar vermeyeceğinden emin olabilirler (Şekil 3) [3]. 


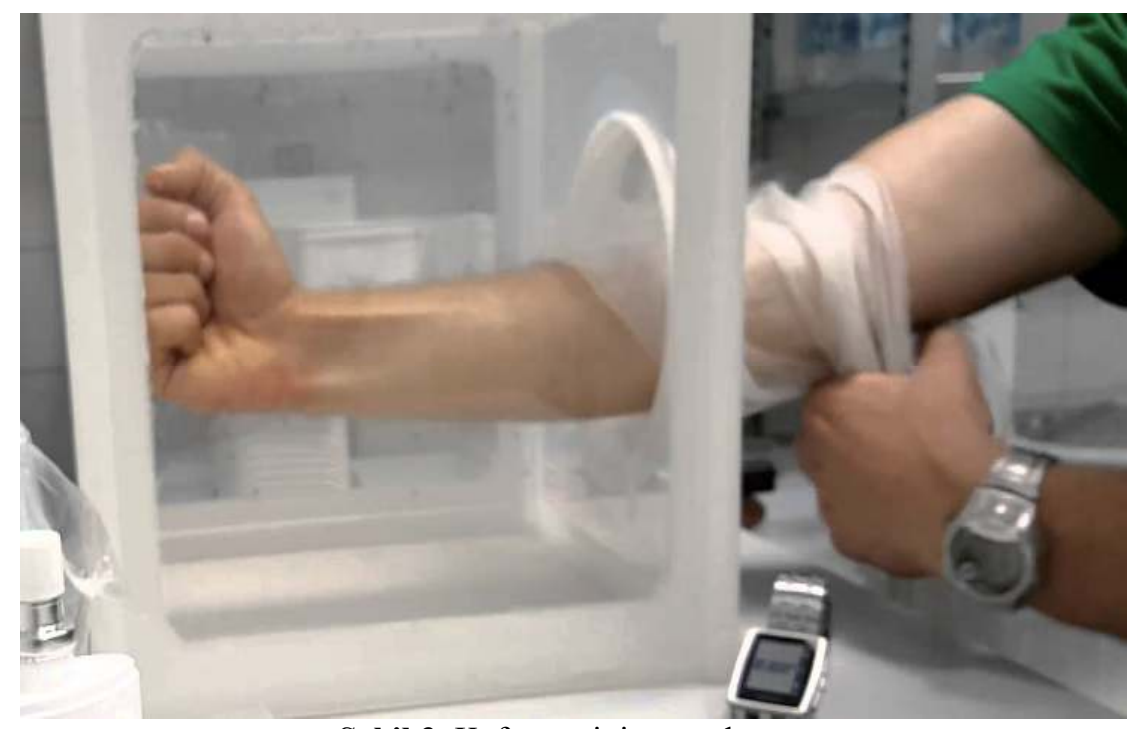

Şekil 3. Kafes testinin uygulanış1.

Dünya sağlık örgütü standartlarına göre (WHO 2009) 40 × 40 x $40 \mathrm{~cm}$ boyutlarında kare test kafeslerine 200 adet dişi sivrisinek doldurulur. Sivrisineklerin hiç doğum yapmamış olması ve testten 1 gün önce kafese konulmaları gerekir. Test süresi 3 dakikadır ve bu süre içerisinde kola inen sivrisinekler sayılır. Test ürünleri gönüllülerin önkollarına uygulanır ve her 30 veya 60 dakikada bir tekrar edilir.

Kumaşın sivrisinek koruma aktivitesi, aşağıda verilen yüzde koruma formülü ile hesaplanır:

Sivrisinekten koruma yüzdesi (\%) : (U - T)/U x 100

Burada $U$, muamele edilmemiş numuneye gelen sinek sayısıdır. T ise muamele edilmiş kumaşa gelen sinek sayısıdır $[3,4,5]$.

\subsection{Koni testi}

$\mathrm{Bu}$ yöntem insan deneği kullanılmadığı için kafes testine göre avantaj sağlar. Ancak bu yöntem daha az kullanılmaktadır. Test, 3 dakikalık maruziyet süresinde ve $27{ }^{\circ} \mathrm{C}$ 'de yapılır [6]. Koni testi, WHO 1998 test standartlarına göre yapılan bir testtir. Standart plastik kovanlar, işlem görmüş test yüzeyine sabitlenir (Şekil 4). Daha sonra, beş adet dişi sivrisinek, bir aspiratör ile koni içine aktarılır ve üç dakika boyunca kovucu aplike edilmiş kumaş yüzeyine maruz bırakılır. Maruziyet sonrası sivrisinekler konilerden çıkarılır ve ilaç içermeyen havada gözlem için küçük kafeslere yerleştirilir. Hareketsiz sivrisineklerin sayısı, çıkarıldıktan bir saat sonra sayılır ve ölü oranı 24 saat sonra belirlenir. Her test yüzeyi, toplamda 50 adet sivrisinek gözlenecek şekilde on defa tekrarlanır. Ek olarak, doğal ölüm oranı, işlem görmemiş bir başka kumaş için de 50 adet sivrisineğe test uygulanır [8].

Test sonucunda sivrisinek ölüm yüzdesi aşağıdaki formül ile hesaplanır:

\% Sivrisinek ölüm oranı: (MR-MC) / (100-MC) x 100 
Burada MR, işlem görmüş ürün kullanarak ölen sinek sayısını, MC ise kontrol ürünü kullanıldığındaki ölü sivrisinek sayısıdır [3].

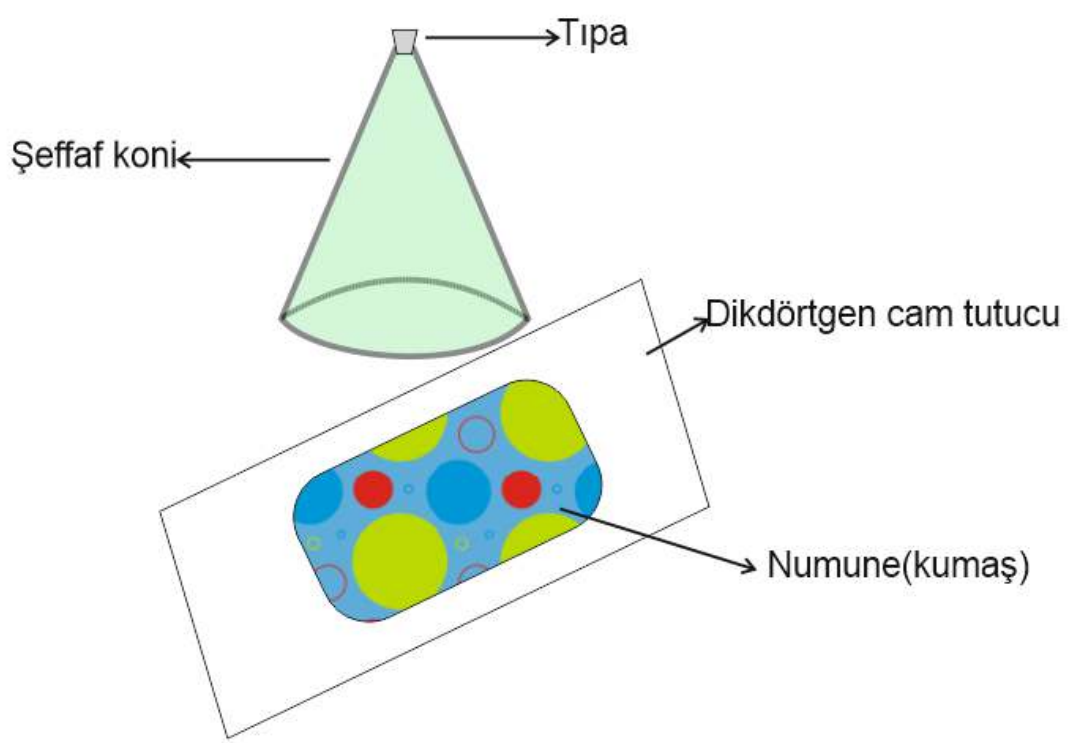

Şekil 4. Koni testinin gösterimi

\subsection{Eskito oda testi}

$\mathrm{Bu}$ yöntem, sivrisineğin işlem görmüş materyalle görmemiş materyal arasındaki farkın sivrisineklerin hareketi gözlenerek elde edilmesi esasına dayanır. $\mathrm{Bu}$ testte de koni testinde olduğu gibi insanlar denek olarak kullanılmaz. Sivrisinekler gece boyunca ya da testten en az 4 saat önce aç bırakılır. Maruziyet süresi, 10 ve 30 dakika olur. Sivrisinek kovucu yüzdesi, aşağıdaki formül kullanılarak hesaplanmıştır:

$\%$ Sivrisinek kovucu: $(\mathrm{NES}+\mathrm{NDE}) /(\mathrm{NEX}) \times 100$

NES değeri, kaçan sivrisinek sayısına karşılık gelirken, NDE değeri ölmüş sivrisinek sayısıdır. NEX değeri ise teste maruz bırakılan sivrisinek sayısıdır.

$\mathrm{Bu}$ yöntem sivrisinek kovucu uygulanmış ve uygulanmamış ürünlerin karşılaştırılması için daha uygun bir yöntemdir [3], [6].

\section{Sonuç}

Sivrisinek kovucu olarak kullanılan kimyasallar insan ve çevre için zehirli olabilmektedir. Aynı zamanda sinekler bu kimyasallara karşı direnç kazanırlar. Bu nedenle sivrisinek gibi eklem 
bacaklıların uzaklaştırılmasında fiziksel çözümlere odaklanmak çevre ve insan sağlığı açısından daha iyi sonuçlar doğuracaktır.

\section{Kaynakça}

[1] Sakulku U, Nuchuchua O, Uawongyart N., Puttipipatkhachorn S., Soottitantawat A., Ruktanonchai U., Characterization and mosquito repellent activity of citronella oil nanoemulsion, International Journal of Pharmaceutics 372 (2009) 105-111.

[2] Tavares, M., da Silva M.R.M., de Siqueira, L.B.O., Rodrigues R.A.S., d'Almeida, L.B., dos Santos, E.P., Ricci-Júniora E., Trends in insect repellent formulations: A review, International Journal of Pharmaceutics, Volume 539, Issues 1-2, 25 March 2018, Pages 190-209.

[3] Xin J. H., Wang X. W., Insect-repellent textiles, Engineering of High-Performance Textiles, Ed. Xin J.H., Miao M., The Textile Institute Book Series, 335-348.

[4] Barnard D. R., Bernier U. R., Xue R., Debboun M., Standard Methods for Testing Mosquito Repellents, Taylor \& Francis Group, LLC, 2006.

[5] https://www.biogents.com/arm-in-cage-test/

[6] Anuar A.A., Yusof N., Methods of imparting mosquito repellent agents and the assessing mosquito repellency on textile, Fashion and Textiles, December 2016, 3:12.

[7] Specos, M. M., Garcia, J.J., Tornesello, J., Marino, P., Della Vecchia, M., Tesoriero, M. D. and Hermida, L. G. (2010) Microencapsulated citronella oil for mosquito repellent finishing of cotton textiles, Transactions of The Royal Society of Tropical Medicine and Hygiene, Volume 104, Issue 10, 1 October 2010, Pages 653-658.

[8] https://www.biogents.com/contract-research-who-cone-test/

[9] Pennetier C., Bouraima A., Chandre F., Piameu M., Etang J., Rossignol M., Sidick I., Zogo B., Lacroix M., Yadav R., Pigeon O., Corbel V., Efficacy of Olyset ${ }^{\circledR}$ Plus, a New Long-Lasting Insecticidal Net Incorporating Permethrin and Piperonil-Butoxide against Multi-Resistant Malaria Vectors, Plos one, Volume 8 | Issue 10, 2013.

[10] WHO/HQ, Report of The Thirteenth Whopes Working Group Meeting, Geneva, 28-30 July 2009.

[11] Sibanda M., Focke W., Braack L., Leuteritz A., Brünig H., Tran N. H. A., Wieczorek F., Trümper W., Bicomponent fibres for controlled release of volatile mosquito repellents, Materials Science \& Engineering C 91 (2018) 754-761.

[12] R. Anitha, T. Ramachandran, R. Rajendran and M. Mahalakshmi, Microencapsulation of lemon grass oil for mosquito repellent finishes in polyester textiles, Elixir Bio Phys. 40 (2011) 5196-5200.

[13] https://www.unicef.org/media/media 81674.html

[14] https://www.epa.gov/insect-repellents/repellent-treated-clothing

[15] Raja A., Kawlekar S., Saxena S., Arputharaj A., Patil PG., Mosquito protective textiles - A review, International Journal of Mosquito Research 2015; 2(4): 49-53.

[16] Shannon, K. (1988). Protective garment for protection against mosquitoes and other insects: google patents, Patent No: US4716594A.

[17] Rozendaal J. A., (1997), Vector control: Methods for use by individuals and communities, World Health Organization (WHO), Geneva.

[18] Fei B., Xin J. H., N, N-diethyl-m-toluamide-Containing Microcapsules for Bio-Cloth Finishing, Am. J. Trop. Med. Hyg., 77(1), 2007, pp. 52-57. 
[19] Ramya K., Maheshwari V., Development of Eco Friendly Mosquito Repellent Fabric Finished with Andrographis Paniculata Plant Extracts, International Journal of Pharmacy and Pharmaceutical Sciences, Vol 6, Issue 5, 2014.

[20] Miró Specos M. M., García J. J., Tornesello J., Marino P., Microencapsulated citronella oil for mosquito repellent finishing of cotton textiles, Transactions of the Royal Society of Tropical Medicine and Hygiene 104 (2010) 653-658.

[21] Pennetier C., Chabi J., Martin T., Chandre F., Rogier C., Hougard J. M. Pages F., New protective battle-dress impregnated against mosquito vector bites, Pennetier et al. Parasites \& Vectors 2010, 3:81.

[22] Troutman S. L., Laundry additive for the treatment and prevention of bed bugs, google patents, Patent No: US20100166818A1. 